\title{
Aorto-Pulmonary Window, an Unrecognized Cause of Heart Failure in Infants: A Case Report
}

\author{
Mohammed Ech-Chebab, Ayyad Ghannam, Aziza El Ouali, Maria Rkain, Noufissa Benajiba, \\ Abdeladim Babakhouya
}

Department of Pediatrics, Mohammed VI University Hospital Center of Oujda, Oujda, Morocco

Email: med.ech.chebab@gmail.com

How to cite this paper: Ech-Chebab, M., Ghannam, A., El Ouali, A., Rkain, M., Benajiba, N. and Babakhouya, A. (2020) Aorto-Pulmonary Window, an Unrecognized Cause of Heart Failure in Infants: A Case Report. World Journal of Cardiovascular Diseases, 10, 678-681. https://doi.org/10.4236/wjcd.2020.109065

Received: August 19, 2020

Accepted: September 22, 2020

Published: September 25, 2020

Copyright @ 2020 by author(s) and Scientific Research Publishing Inc. This work is licensed under the Creative Commons Attribution International License (CC BY 4.0).

http://creativecommons.org/licenses/by/4.0/

\begin{abstract}
Introduction: The aorto-pulmonary window is a rare congenital heart disease. It is a defect between the ascending aorta and the trunk of the pulmonary artery upstream of the pulmonary bifurcation. Once the diagnosis is made, surgery must be performed quickly to avoid progression to pulmonary arteriolitis. We report the case of a 4-month-old infant in whom we made the diagnosis of aorto-pulmonary window type I. He was able to benefit from an open heart surgery at FES with an excellent result after closing the window. Conclusion: The aorto-pulmonary window is a rare congenital heart defect, the diagnosis of which must be made as early as possible in order to avoid the progression to pulmonary hypetension and heart failure.
\end{abstract}

\section{Keywords}

Aorto-Pulmonary Window, Heart Failure, Infant, Congenital

\section{Introduction}

The aorto-pulmonary window is a rare congenital heart disease. It is a defect between the ascending aorta and the trunk of the pulmonary artery upstream of the pulmonary bifurcation. Once the diagnosis is made, surgery must be performed quickly to avoid progression to pulmonary arteriolitis.

We report the case of a 4-month-old infant in whom we made the diagnosis of aorto-pulmonary window type I. He was able to benefit from an open-heart surgery at the university hospital of FES with an excellent result after the closing the window.

\section{Case Report}

4 month old male infant from a non-consanguineous marriage of a twin pregnancy (healthy twin brother) admitted for fatigability at feedings with weight 
stagnation (weight: $5 \mathrm{~kg}$ ) in whom clinical examination finds a discontinuous left lateral systolic murmur on cardiac auscultation with a hepatic overflow. The Echocore shows a Richardson type Iaorto-pulmonary window measuring $8 \mathrm{~mm}$ with aorto-pulmonary shunt and sign of hyperflow (Figure 1). The infant was operated on in FEZ university hospital center after diagnosis by transaortic approach using a median sternotomy and cardiopulmonary bypass. The patient had good recovery from operation. His respiratory symptoms decreased after surgery. Echocardiography was performed and showed normal left ventricular function, and no residual aortopulmonary defect.

\section{Discussion}

The aorto-pulmonary window is a rare non-cyanogenic congenital heart disease, it is found in $0.1 \%$ to $0.6 \%$ of cases of patients with congenital heart disease [1] [2]. Very few cases have been described in Africa [3]. It can be isolated or associated with other malformations, the most common of which are interventricular communication, pulmonary atresia, interruption of the aortic arch or coarctation of the aorta [4]. In our observation we found an isolated form. This is an abnormality caused by a defect in the development of the aorto-pulmonary spiral septum which normally separates the aorta from the pulmonary artery. The aorto-pulmonary window makes an abnormal communication between the left edge of the ascending aorta and the right edge of the pulmonary trunk [5]. Antenatal diagnosis is possible but sometimes difficult in combination with other cardiovascular abnormalities [4]. The clinical symptomatology is that which is conventionally found in congenital heart disease with pulmonary hyperflow by left-right shunt, as in the interventricular communication and the persistence of the ductusarteriosus. Clinical examination finds signs of pulmonary hyperflow associated with a arterial hyperpulsality, with hyperkinetic heart and peak left

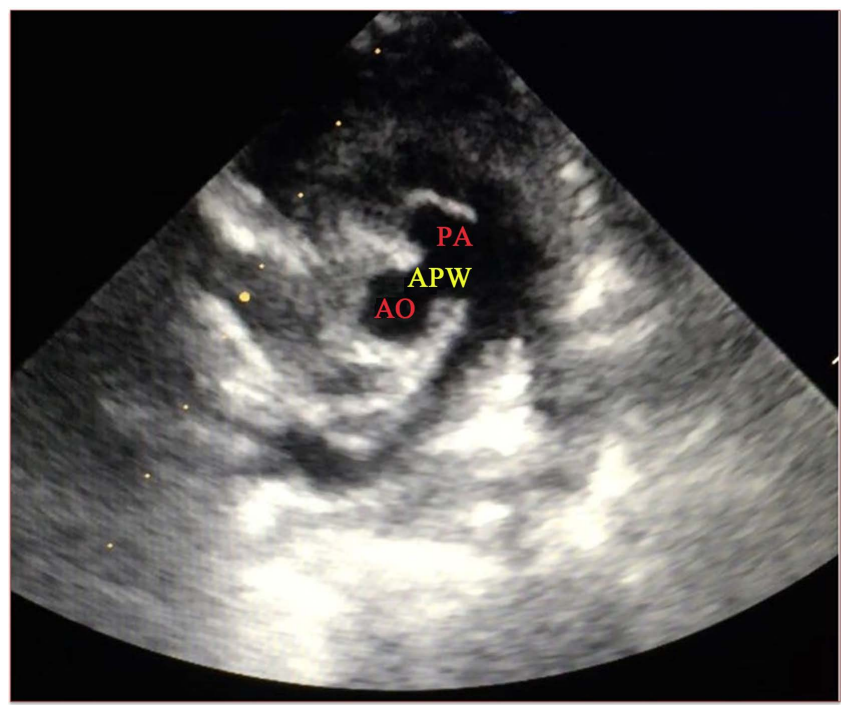

Figure 1. High parasternal short-axis echocardiogram is showing the aortopulmonary window (APW) between the ascending aorta (Ao) and main pulmonary artery (PA). 
shock deviation. The often intense and sometimes quivering systolic murmur is found at the left edge of the sternum. When the aortopulmonary window is small and restrictive it can be well tolerated, which is why in $15 \%$ to $20 \%$ of cases it is discovered in older children or in adulthood [5] [6]. In our case, the patient presented with a symptomatology typical of infant heart failure: tachypnea, hepatomegaly, weight loss and mild systolic murmur on auscultation. Closure of APW is indicated in all patients and it should be performed as soon as possible after diagnosis. Successful repair of an APW was reported from several years ago and many authors have reported their results [7]. Our patient was operated successfully without postoperative complications.

\section{Conclusion}

The aorto-pulmonary window is a rare congenital heart defect. The diagnosis should be made as early as possible on the basis of clinical radiological suspicion and confirmation by ultrasound or the presence of signs of left-to-right shunt without interventricular communication or persistence ductus arteriosus should suggest the diagnosis of aorto-pulmonary window. Early surgical closure or use of the device is indicated as soon as the diagnosis is made to prevent congestive heart failure and pulmonary hypertension.

\section{Conflicts of Interest}

The authors declare no conflicts of interest regarding the publication of this paper.

\section{References}

[1] Bagtharia, R., Trivedi, K.R., Burkhart, H.M., et al. (2004) Outcomes for Patients with an Aortopulmonary Window, and the Impact of Associated Cardiovascular Lesions. Cardiology in the Young, 14, 473-480. https://doi.org/10.1017/S1047951104005025

[2] Konstantinov, I.E., Karamlou, T., Williams, W.G., et al. (2006) Surgical Management of Aortopulmonary Window Associated with Interrupted Aortic Arch: A Congenital Heart Surgeons Society Study. The Journal of Thoracic and Cardiovascular Surgery, 131, 1136-1141e2. https://doi.org/10.1016/j.jtcvs.2005.03.051

[3] Mori, K., Ando, M., Takao, A., et al. (1978) Distal Type of Aortopulmonary Window: Report of Four Cases. British Heart Journal, 40, 681-689.

https://doi.org/10.1136/hrt.40.6.681

[4] Jacobs, J.P., Quintessenza, J.A., Gaynor, J.W., et al. (2000) Congenital Heart Surgery Nomenclature and Database Project: Aortopulmonary Window. The Annals of Thoracic Surgery, 69, S44-S49. https://doi.org/10.1016/S0003-4975(99)01236-9

[5] Berry, T.E., Bharati, S., Muster, A.J., et al. (1982) Distal Aortopulmonary Septal Defect, Aortic Origin of the Right Pulmonary Artery, Intact Ventricular Septum, Patent Ductusarteriosus and Hypoplasia of the Aortic Isthmus: A Newly Recognized Syndrome. American Journal of Cardiology, 49, 108-116. https://doi.org/10.1016/0002-9149(82)90284-3

[6] Collinet, P., Chatelet-Cheront, C., Houze de l'Aulnoit, D. and Rey, C. (2002) Pre- 
natal Diagnosis of an Aorto-Pulmonary Window by Fetal Echocardiography. Fetal Diagnosis and Therapy, 17, 302-307.

[7] Gross, R.E. (1952) Surgical Closure of an Aortic Septal Defect. Circulation, 5, 858-863. https://doi.org/10.1161/01.CIR.5.6.858 